\title{
Usuário submetido à endoscopia digestiva alta e seu acompanhante: perfil e expectativas
}

Recebido em 15/08/2012

Aprovado em: 16/05/2013
Ilza Schmidt de Brito Selhorst ${ }^{1}$ Maria Bettina Camargo Bub² Juliana Balbinot Reis Girondi ${ }^{3}$

Resumo: Pesquisa qualitativa que objetivou identificar o perfil e as expectativas do usuário submetido à Endoscopia Digestiva Alta num Centro Endoscópico de um hospital universitário e as principais necessidades de educação em saúde apresentadas por estes e seus acompanhantes. Os dados foram coletados entre abril e maio de 2011, através de entrevistas semi estruturadas, com vinte e um usuários e dezenove acompanhantes. Os resultados apontaram para a importância de implantar o acolhimento como uma prática de saúde, conhecer quem são os envolvidos no recebimento do cuidado de saúde e para a necessidade de construção de um protocolo de acolhimento.

Descritores: Assistência de enfermagem, Endoscopia, Acolhimento

Usuario realizó endoscopia y su compañero: perfil y expectativas

Abstract: Qualitative research attempts to identify the user profile and expectations submitted to Upper endoscopy Endoscopic Center in a university hospital and the main needs of health education provided by these and their companions. Data were collected between april and may 2011 through semi-structured interviews, with twenty-one users and nineteen companions. The results point to the importance of deploying the host as a health practice, identify who are involved in receiving health care and the need to build the host protocol.

Descriptors: Nursing Assistance, Endoscopy, User Embracement

\section{User underwent endoscopy and his companion: profile and expectations}

Resumen: La investigación cualitativa trata de investigar el perfil y expectativas de usuario presentado al Alto Centro de endoscopia en un hospital y las principales necesidades de educación para la salud proporcionados por éstos y sus compañeros. Los datos fueron recogidos entre abril y mayo de 2011 por entrevistas semi-estructuradas, con veintiún usuarios y compañeros diecinueve. Los resultados apuntan a la importancia de implementar el host como una práctica de salud, identificar los que están involucrados en la recepción de la asistencia sanitaria y la necesidad de constrir el protocolo de acogida. Descriptores: Asistencia de enfermería, Endoscopia, Acogimiento

\section{INTRODUÇÃO}

A endoscopia consiste em um método de investigação médica, com fins diagnósticos e de tratamento, onde se examina a mucosa da parte superior do trato gastrointestinal com um aparelho chamado endoscópio(1).

Para desenvolver uma assistência de qualidade é importante conhecer quem são os envolvidos que recebem o cuidado de saúde, como percebem o serviço, que orientações esperam receber e as expectativas em relação à equipe. $O$ procedimento é rápido e o pouco tempo que os usuários permanecem no local dificulta o estabelecimento de vínculos com esses indivíduos e seus acompanhantes. Logo, a opção de se trabalhar com o acolhimento tem sentido se este for compreendido como parte do processo de produção de saúde, como algo que qualifica a relação entre profissional e usuários; como uma atitude de inclusão(2)

Assim, o acolhimento no processo de trabalho em saúde regula o acesso e permitir e/ou facilita a abertura dos serviços com responsabilidade de todos, trabalhador de saúde, gestores, usuários e família(3).

Nesse contexto, esse estudo objetivou identificar o perfil e as expectativas do usuário submetido à Endoscopia Digestiva Alta num Centro Endoscópico de um hospital universitário e as principais necessidades de educação em saúde apresentadas por estes e seus acompanhantes.

\section{MÉTODOS}

Estudo qualitativo exploratório realizado no Centro Endoscópico do Hospital Universitário Dr. Polydoro Ernani São Thiago da Universidade Federal de Santa Catarina.

A coleta de dados ocorreu no período de abril e maio de 2011, através de entrevistas semi estruturadas. Participaram 21 usuários e 19 acompanhantes, mediante a assinatura do Termo de Consentimento Livre e Esclarecido. Para tratamento dos dados utilizou-se a Análise de Bardin.

A fim de preservar o sigilo e anonimato utilizou-se a letra "U" acrescido com os números ordinais para identificar os usuários e a letra " $\mathrm{A}$ " também com números sequenciais para relacionar-se ao acompanhante.

O projeto de pesquisa foi aprovado pelo Comitê de Ética em Pesquisa com Seres Humanos da Universidade Federal de Santa Catarina pelo protocolo de número 1857/2010.

\section{RESULTADOS E DISCUSSÃO}

Em relação ao perfil dos vinte e um usuários $71,5 \%$ eram do sexo feminino e $28,5 \%$ do sexo masculino. Houve prevalência da faixa etária entre 41 a 50 anos (28,6\%). Quanto à escolaridade, observou-se um predomínio de $57 \%$ com ensino fundamental e médio. Sobre o estado civil, $62 \%$ eram casados ou tinham união estável. Em relação à atividade laboral, $62 \%$ eram do lar e/ou aposentados. Estavam realizando pela primeira vez o exame $57 \%$ dos participantes.

'Enfermeira. Mestre em Enfermagem pela Universidade Federal de Santa Catarina. Enfermeira chefe do Serviço de Enfermagem Ambulatorial do Hospital Universitário Dr. Polydoro Ernani de São Thiago (HU/UFSC). E-mail: ilza.sbs@ig.com.br.

${ }^{2}$ Doutora em Enfermagem. Professora Adjunta do Departamento de Enfermagem da UFSC

${ }^{3}$ Enfermeira. Doutora em Enfermagem pela Universidade Federal de Santa Catarina. Docente do Departamento de Enfermagem da Universidade Federal de Santa Catarina. 
Quanto ao perfil dos acompanhantes foram entrevistadas dezenove pessoas, sendo $84 \%$ do sexo masculino e $16 \%$ do sexo feminino. A prevalência em relação à idade foi entre 51 a 60 anos (63\%). Na escolaridade prevaleceu o ensino fundamental e médio com $74 \%$ dos acompanhantes, 58\% estavam pela primeira vez acompanhando uma pessoa que seria submetida a esse exame.

Avaliando o perfil dos usuários de saúde constata-se que a maioria dos que procuram o serviço são mulheres na faixa etária entre 41-50, geralmente aposentadas ou exercendo atividades no lar.

Pesquisas apontam que a pré-menopausa inicia-se aproximadamente aos 45 anos e a menopausa das mulheres brasileiras ocorrem em média aos 48,6 anos de idade ${ }^{(4)}$. Nessa fase ocorre carência estrogênica, envelhecimento, mudanças de vida da pessoa e às vezes os recursos destinados à sua adaptação estão desgastados contribuindo com o aparecimento de várias doenças. Nessa etapa normalmente as mulheres sofrem perdas, mudanças físicas, co-morbidades (hipertensão, diabetes), aposentadoria e "síndrome do ninho vazio". Pesquisas constatam que ocorre maior tendência à ansiedade em mulheres casadas, que são $47,4 \%$ da amostra deste estudo. A ansiedade costuma apresentar como sintomas a inquietação, insegurança e tensão muscular ${ }^{(5)}$.

Dor e mal estar na parte superior do abdômen foi à queixa principal para realizar o procedimento por parte dos usuários que procuram o serviço. Existe ligação entre estados de ansiedade, estresse, problemas de apetite com o aparelho digestivo. Ansiedade pode provocar dispepsia, pois a pessoa ansiosa tende inspirar e engolir ar, o que provoca distensão gástrica e pode aumentar a percepção das sensações desagradáveis por parte da pessoa.

Estou muito agitada e nervosa nesta fase da minha vida, meu estômago dói direto, já fui ao médico e agora vim fazer a Endoscopia (U1).

Outro aspecto relevante a considerar é que as mulheres são, segundo estatísticas, as principais usuárias dos serviços de saúde. Atualmente as mulheres são a maioria da população brasileira $(50,77 \%)$ e procuram o SUS para o próprio atendimento ou acompanhando seu familiar ${ }^{(5)}$.

Com relação aos acompanhantes constata-se que a maioria foi do sexo masculino, o que diverge da literatura, pois geralmente são as mulheres que desempenham esse papel $^{(5)}$. Uma explicação pode estar relacionada ao fato do serviço exigir a presença de acompanhante para a realização do exame, assim como proibir a direção de veículos, uma vez que o usuário geralmente é sedado. A maioria dos acompanhantes constituía-se de esposos, pais, filhos e sobrinhos das usuárias, os quais eram também habilitados para dirigir.

Não costumo vir com minha mulher no médico e nos exames porque tenho que trabalhar, mas dessa vez fui obrigado porque vão botá-la pra dormir e a minha sogra não vai conseguir levá-la pra casa (A14).

A análise de dados permitiu a formação de três categorias que são apresentadas.

\section{Conhecimento prévio acerca dos cuidados relacionados ao exame endoscópico}

Conforme referido pelos entrevistados, as orientações recebidas tanto nas Unidades Básicas de Saúde como no hospital de ensino foram restritas as exigências mínimas necessárias para realizar o exame: todos estavam cientes da necessidade de jejum nas horas que antecede o exame e da obrigatoriedade de trazerem a autorização e a solicitação médica do exame.

Apesar disso, 33\% dos entrevistados referiram não saber sobre a necessidade de acompanhante, em função da sedação, desconhecendo, portanto, a impossibilidade de dirigir automóvel ou motos, embora essas informações constassem na guia de marcação do exame.

Vim de moto, agora não sei como ir para casa, o meu companheiro é que vai guiar, mas a moça da recepção disse que não posso ir embora assim. Estou vendo que estava escrito na folha de autorização, mas não li e não disseram nada no posto (U5).

star na parte

Com relação ao hospital referiram só terem conversado até aquele momento com a recepcionista, que é uma estudante de um curso de graduação e não tem conhecimentos na área da saúde, desenvolvendo apenas atividades burocráticas. Sobre as informações recebidas por esta, destacam que foram questionados sobre o jejum de 12 horas, presença de acompanhante, se sabia que não poderia dirigir após o procedimento e/ou andar de moto. Foram conferidos os documentos obrigatórios como: pedido de exame, autorização do Sistema de Regulação (SISREG), exames anteriores, documento ou número do prontuário do hospital.

Além disso, foi solicitada pela recepcionista a leitura e assinatura do Termo de Consentimento para realização do procedimento. Sobre o termo legal de consentimento para o exame, que é uma rotina da instituição, a grande maioria dos usuários e acompanhantes relatou dificuldade para compreender o que estava escrito. Esse fato torna-se preocupante, uma vez que o não entendimento deste documento pode estar implicando na realização do exame sem a necessária clareza de seus riscos. Implica sobretudo em uma questão ética, pois os termos de consentimento devem ser livres e esclarecidos de modo a permitir por parte dos sujeitos o exercício de sua

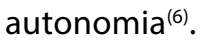

A mocinha lá da frente só perguntou o mesmo que o rapaz lá do posto. Viu a autorização e o pedido, me deu uma folha para ler e escrever. Tive que pedir para minha acompanhante, se ela não entendesse ia pedir para a mocinha fazer pra mim. Estava muito difícil de entender e me mandaram ficar esperando (U12).

Somente $48 \%$ dos usuários e seus acompanhantes tinham algum conhecimento prévio sobre o exame endoscópico, mas que se restringia a como deveriam proceder para a realização do mesmo em relação à alimentação e atestado médico para justificar a ausência ao trabalho. Ao serem questionados sobre como adquiriram essas informações mencionaram vir de familiares, amigos e conversas na sala de recepção com 
pessoas que já tinham sido submetidas ao procedimento.

Quando ela falou que vinha fazer endoscopia eu falei que estava tudo certo, mas na verdade fui perguntar para os meus colegas de trabalho como era o exame, depois tivemos mais uma ideia conversando aqui na sala de espera com os outros familiares(A9).

Dos entrevistados $85 \%$ referiram que preferiam que as orientações fossem passadas verbalmente, alguns mencionaram ter preferência por um trabalhador da enfermagem como a pessoa indicada para essa função, antes do procedimento, independente se o local fosse a unidade básica de saúde ou o hospital.

Ainda carece de orientação, mas eu prefiro que a enfermeira converse e explique lá no postinho ou aqui quando a gente chega. Muitas vezes vem escrito, mas normalmente a gente não lê ou não entende o que está escrito(U20).

A constatação da ausência ou insuficiência de informações ao usuário e seu acompanhante quanto aos diversos aspectos e etapas que envolvem o exame endoscópico contraria os princípios da política nacional de humanização, no que diz respeito à participação do usuário e sua rede de relações em seu processo de saúde doença ${ }^{(7)}$. Faz pensar no modo como estão sendo acolhidos estes usuários nas unidades básicas de saúde e sobretudo, no próprio serviço e a necessidade de ações profissionais que minimizem esta realidade.

\section{Acesso e organização do sistema: pontos positivos}

Nesse eixo temático foi constatado que todos os encaminhamentos para o hospital foram realizados pelas Unidades Básicas de Saúde, via marcação do Sistema de Regulação (SISREG), pelo Sistema Único de Saúde (SUS).

Uma vantagem é que fiz tudo pela rede pública. Estava sentindo muito dor na barriga, fui atendido pelo médico do posto pertinho lá de casa, foi dado o remédio e o pedido foi deixado lá. Tudo pelo SUS, sem ter que tirar o dinheiro do meu bolso (U7).

Para 22,2\% dos usuários o período de espera para ser submetido ao procedimento, desde o momento da entrega da solicitação do exame na unidade básica até a sua realização foi superior a quatro meses; $44,4 \%$ esperaram cerca de dois a quatro meses e $33,3 \%$ conseguiram ser encaminhados para realizar o exame antes de completar trinta dias.

A marcação de exames na rede pública observa conceitos como os exames e consultas de rotina, que seguem a ordem cronológica de entrada na lista; os de prioridade, que são aqueles cuja demora de marcação alterem sobremaneira a conduta seguida ou impliquem na quebra do acesso a outro procedimento e os urgentes, que são aqueles que não podem aguardar na lista de espera, já que podem levar a um comprometimento clínico. É responsabilidade do médico regulador a organização do acesso a estes casos urgentes8.
O fato de o atendimento ser pelo SUS, com a marcação no mesmo local que consultou foi considerado por todos muito bom, porque evitou deslocamentos desnecessários por parte do usuário, filas, economia de tempo e custos com o transporte.

Outro ponto referido de forma positiva foi com relação à estrutura física da instituição, com uma boa sinalização, presença de elevadores, escada e rampas que facilitam o acesso aos deficientes. As senhas para atendimento entregues na área de portaria e na recepção do centro endoscópico permitiu maior agilidade e organização no atendimento.

Qualquer projeto de humanização da assistência em prol da uma melhor relação equipe-usuário deve estar vinculada a mudanças nos aspectos gerenciais e organizacionais dos serviços, assim como nas estruturas físicas, de forma a articular avanço tecnológico e acolhimento melhores condições de trabalho e processos de comunicação ${ }^{(9)}$.

Foi simples chegar aqui para fazer o exame, deu até gosto, tudo está organizado, bem sinalizado, na recepção pega a senha e explicam tudo direitinho (U12).

A resolutividade do trabalho realizado pela equipe de trabalhadores do Centro Endoscópio foi referida como uma demonstração da qualidade do serviço. O usuário se dirige alou que vinha para o local da realização do exame, fazo procedimento e sai com o laudo pronto.

Acesso e organização do sistema: pontos negativos

Como ponto negativo foi colocado por $87 \%$ dos entrevistados que o local onde os exames foram agendados não era próximo da sua residência, não houve oportunidade do usuário fazer a opção por um serviço mais próximo. Em muitos casos foi necessário meio de transporte para chegar até o hospital, gerando em grande parte das situações a dependência do usuário de outrem para seu deslocamento.

No município, os exames e atendimentos médico especializado estão concentrados na região central e continental. É verídica a afirmação que a ampliação da rede básica tem contribuído para melhorar a acessibilidade geográfica, porém muitas vezes evidencia-se uma desproporção entre oferta, capacidade de atendimento e demanda ${ }^{(10)}$.

Outra dificuldade apontada por $91 \%$ dos entrevistados foi a demora em obter consultas médicas com especialistas e exames de alta complexidade, além do fato que cada unidade básica de saúde tem os seus próprios critérios e rotinas para agendar as consultas e procedimentos.

Aspecto relevante foi referido por $64 \%$ dos entrevistados sobre a dificuldade de se obter informação sobre o andamento do pedido, se o mesmo tem previsão de marcação ou se já foi enviado para o sistema de regulação. A declaração queixosa evidencia esse achado:

Nunca se sabe quando vai conseguir um exame ou consulta. Vê o caso do meu pai, foram quatro meses de pedido e nada de retorno. Eu ligava toda semana para perguntar. Acho que a escrituraria do posto não gostou porque eu insistia. Chegou a ser malcriada, perdi a paciência. Fiz reclamação na Ouvidoria do município, hoje estou aqui (A2). 


\section{CONSIDERAÇÕES FINAIS}

Os resultados desse estudo mostraram a deficiência nas orientações em saúde fornecidas ao usuário e acompanhante antes de serem submetidos ao procedimento de endoscopias. Considera-se relevante conhecer quem são esses indivíduos, pois subsidiará a enfermagem na elaboração das ações, de forma segura e acolhedora, prestando orientações na consulta de enfermagem pré-exame, participando dos cuidados durante e após o procedimento; além de possibilitar a enfermeira maior autonomia na reorganização do processo de trabalho.

\section{Referências}

1.Sociedade Brasileira de Endoscopia Alta. Endoscopia digestiva alta [internet].[citado em 2010 Jun 5]. Disponível em: http://www. sobed.org.br/web/site/unico.aspx?id_secao=72.

2. Ministério da Saúde (BR). Acolhimento e classificação de risco nos serviços de urgência. Brasília: Ministério da Saúde; 2009.

3. Schneider DG et al. Acolhimento ao paciente e família na unidade coronariana. Texto Contexto Enferm 2008; 17(1): 81-9.

4 Hable HW, Fonseca A M, Bagnoli VR. Epidemiologia do Climatério. Revista Sinopse de Ginecologia e Obstetrícia 2002; 2: 36-9.

5 Pereira WM et al. Ansiedade no climatério: prevalência e fatores associados. Rev Bras Crescimento Desenvolvimento Hum. 2009; 19(1): 89-97.

6 Oliveira VL et al. O uso do termo de consentimento livre e esclarecido na prática médica.Revista Bioética 2010; 18 (3):70524.
7. Ministério da Saúde (BR). HumanizaSUS - Política Nacional de Humanização. A humanização como eixo norteador das Práticas de Atenção e Gestão em todas as instâncias do SUS. Brasilia: Ministério da Saúde; 2004

8. Ministério da Saúde (BR). Portal da Saúde SUS. Protocolos clínicos e diretrizes terapêuticas - PCDT. [internet].[citado em 2010 Set 26]. Disponível emhttp://portal.saude.gov.br/portal/saude/profissional/ visualizar_texto.cfm?idtxt=35490\&janela $=1$.

9. Ministério da Saúde (BR). . HumanizaSUS - Política Nacional de Humanização. A humanização como eixo norteador das Práticas de Atenção e Gestão em todas as instâncias do SUS. Brasília: Ministério da Saúde; 2004

10. Queiroz MVO, Ribeiro EMV, Pennafort VPS. Assistência ao adolescente em um serviço terciário: acesso, acolhimento e satisfação na produção do cuidado. Texto Contexto Enferm. 2010; 19(2): 291-9. 